\title{
Garantia da qualidade e da avaliação: um estudo comparado sobre as decorrências do processo de Bolonha na comunidade dos países de língua portuguesa
}

\author{
Gionara Tauchen* \\ Maria da Conceição Barbosa Rodrigues Mendes** \\ Catia Piccolo Devechi"
}

\section{Resumo}

A Educação Superior, na sociedade de conhecimento do século XXI, vem sendo objeto de múltiplos interesses que colocam, cada vez mais, na agenda política dos Estados, mecanismos para a garantia da qualidade. Por isso, um número crescente de países e instituições, estimulados pelas Conferências, Declarações e Comunicados mundiais, referentes à Educação Superior, passaram a definir uma agenda para a reorganização da estrutura curricular dos cursos e para a organização de sistemas internos e externos de avaliação institucional, entre outros aspectos. Situado nesse contexto, o presente estudo objetiva analisar e discutir as induções, decorrentes do Processo de Bolonha, à organização de mecanismos para garantia da qualidade e de avaliação da ES, no âmbito da Comunidade dos Países de Língua Portuguesa (CPLP), mais especificamente, Brasil, Angola, Moçambique e Cabo Verde. Consideramos fundamental juntar os pontos da rede de intenções e ações supranacionais para compreender os meandros das reconfigurações das políticas educativas locais. Concluímos que a avaliação vem se firmando como um instrumento de regulação da qualidade das IES e de gestão da agenda educacional dos Estados. Por isso, entende-se que a criação de sistemas de avaliação vincula-se à necessidade de regulação dos Estados e à indução da qualidade dos sistemas educacionais, num cenário de diversificação de modelos institucionais, de expansão do acesso à Educação Superior e de integração e de reconhecimento internacional.

Palavras-chave: Avaliação. Qualidade. Processo de Bolonha. Educação Superior.

Professora Adjunta da Universidade Federal do Rio Grande-FURG; docente permanente dos Programas de Pós-Graduação em Educação e em Educação em Ciências: Química da Vida e Saúde. Doutora em Educação (PUC/RS) e Pós-doutora em Ensino-aprendizagem na Universidade Eduardo Mondlane (UEM), Moçambique. E-mail gionaratauchen@furg.br

** Pesquisadora da Universidade Katyavala Bwila/Instituto Superior de Ciências da Educação de Benguela/Angola UKB. Doutora em Ciências da Educação pela Universidade do Minho-Portugal. E-mail saobarbosa67@yahoo.com.br

*** Professora do programa de Pós-Graduação em Educação da Faculdade de Educação da Universidade de Brasília. É mestre em Educação pela Universidade Federal de Santa Maria e doutora em Educação pela Universidade Federal de Santa Catarina. E-mail devechi@unb.br 


\section{Considerações iniciais}

As universidades, ao longo dos tempos, organizaram-se e evoluíram por intermédio de tradições nacionais e, modernamente, têm sido influenciadas por modelos internacionais, especialmente, o francês, o alemão, o inglês e o americano. Sobrevivendo às inúmeras mudanças políticas, econômicas, sociais e culturais as universidades "têm sido instituições essencialmente instrumentais, atendendo necessidades sociais, culturais e políticas" (BROCK, 2009, p. 161). Trata-se de uma adaptação que busca atender a uma série de interesses institucionais, governamentais e comerciais que nem sempre convergem. Santos (1996) explica que as contradições entre as funções tradicionais da universidade (alta cultura, ensino) e as que lhe foram atribuídas, ao longo do século XX (conhecimentos instrumentais, formação de mão de obra), evidenciaram sua incapacidade para atender aos diversos interesses, levando os estados-nações e os agentes econômicos a buscarem meios alternativos para a formação superior, diferenciando-se e ampliando-se as instituições que hoje integram o que denominamos Educação Superior ou Ensino Superior (ES).

Do mesmo modo, em muitos contextos nacionais e educativos são sinalizáveis questionamento em relação à "universidade idealizada" e à "universidade real". Santos (2008), ao referir-se à definição de universidade como uma das questões centrais da sua legitimidade, argumenta que pode facilmente passar por universidade aquilo que não o é, decorrente da acumulação de funções atribuídas à essa ao longo do século XX. Assim, o autor sugere que a redefinição da universidade deve estar entre os desafios dessa instituição no século XXI, pelo que "as reformas devem partir do pressuposto de que só há universidade quando há formação graduada e pós-graduada, pesquisa e extensão" (SANTOS, 2008, p. 47), o que se torna mais premente num panorama em que a globalização assume dimensão considerável.

Incentivadas por políticas governamentais, as universidades são, cada vez mais, induzidas a atuarem na internacionalização da Educação Superior. Morosini (2006) explica que a internacionalização da Educação Superior, no cenário mundial, ampliou-se a partir da década de 1990, e "corrobora para isto a tendência de categorizar a educação como serviço, regulamentada pela OMC, paralelo ao predomínio da concepção de transnacionalização frente à da soberania do estado-nação" (2006, p. 107). Em meio à redefinição do papel e das políticas dos estados-nação, influenciados pela globalização, Morosini (2006) analisa duas perspectivas que relacionam educação e globalização: a primeira refere-se "à existência de uma cultura educacional mundial comum, onde o modelo único seria o modelo certo, prisma de comparação" (2006, p. 111), decorrente do contexto supranacional, de natureza 
ideológica neoliberal. A segunda, evidencia-se na "[...] relação das políticas educacionais com uma agenda globalmente estruturada para a educação" (2006, p. 111).

Nesse cenário, "a educação superior é cada vez mais vista como um elemento para o desenvolvimento sustentável, e o aprendizado continuado se tornou um produto das mudanças sociais" (UVALIC-TRUMBIC, 2009, p. 171). Isso tem imposto a questão da qualidade da educação na agenda das discussões atuais sobre o ensino superior. A Conferência Mundial sobre Educação Superior (WCHE), realizada em Paris, em 1998, por exemplo, constituiu-se em um fórum para o debate sobre as políticas educativas, resultando na "Declaração Mundial sobre Educação Superior no Século XXI: Visão e Ação", que proclamou as missões e funções da ES e os caminhos para promover seu avanço em todo o mundo. No Artigo 11, referente à avaliação da qualidade, se expressa que "a qualidade em educação superior é um conceito multidimensional que deve envolver todas as suas funções e atividades: ensino e programas acadêmicos, pesquisa e fomento da ciência, [...]". Para assegurar essa qualidade, "uma auto-avaliação interna transparente e uma revisão externa com especialistas independentes, se possível com reconhecimento internacional [...]". Propõe, ainda, que sejam "criadas instâncias nacionais independentes e definidas normas comparativas de qualidade, reconhecidas no plano internacional". Então, "será a batalha para regulamentar [...] a ES - pública ou privada - através da noção de assegurar qualidade essencialmente à última fase da competição entre interesses investidos para controlar o que agora se tornou a indústria de conhecimento global?" (BROCK, 2009, p. 161). Fato é que estamos lidando com um fenômeno de proporções globais que, "na nossa terminologia 'politicamente correta' damos o nome de 'garantia de qualidade' para o controle de padrões de conteúdo, ensino e validação" (BROCK, 2009, p. 161).

Como veremos, a "garantia da qualidade" será uma preocupação, progressivamente incorporada pelos estados-nações, os quais promoverão ações para a criação dos Sistemas de Garantia da Qualidade do Ensino Superior. Nesse contexto, nossa análise vincula-se a um dos objetivos primordiais da criação do Espaço Europeu de Ensino Superior: "o incentivo à cooperação Europeia na garantia da qualidade com o intuito de desenvolver critérios e metodologias comparáveis" (DECLARAÇÃO DE BOLONHA, 1999, p. 2, grifo nosso). A Europa do ensino superior, nascida da estratégia da União Europeia de fazer dessa a economia do conhecimento mais competitiva e dinâmica, teve seu início em 1998, com a declaração de Sorbonne, e formalizou-se com a Declaração de Bolonha em 1999, a qual definiu um conjunto de etapas para que os sistemas de ES pudessem construir, até o final de 2010, um Espaço Europeu de ES (EEES), integrado e competitivo, ampliando mundialmente seu protagonismo junto às sociedades do conhecimento. Os objetivos ambiciosos perseguem o aumento da competitividade do EEES, a mobilidade, a comparabili- 
dade e a empregabilidade. As ideias base do Processo de Bolonha pressupõem mecanismos de formação e de reconhecimento de graus acadêmicos homogeneizados, os quais incidem, por consequência na reorganização das estruturas educativas dos sistemas, das instituições e dos cursos de formação.

Assim, um número crescente de países e/ou instituições, estimulados pelas Conferências, Declarações e Comunicados mundiais, referentes à ES, passaram a definir uma agenda para a reorganização da estrutura curricular dos cursos e para a organização de sistemas internos e externos de avaliação institucional, entre outros aspectos. Situado nesse contexto, o presente estudo objetiva analisar e discutir as induções, decorrentes do Processo de Bolonha, à organização de mecanismos para "garantia da qualidade" e de avaliação da ES, no âmbito da Comunidade dos Países de Língua Portuguesa (CPLP), mais especificamente, Brasil, Angola, Moçambique e Cabo Verde.

Para a realização do estudo, de natureza teórica (bibliográfica e documental), nos utilizamos da atualidade dos estudos comparados, entendendo que a compreensão de problemas complexos tem exigido a investigação de contextos diversificados, de modo a elucidar problemas comuns. Por meio dos estudos comparados (COWEN, KAZAMIAS, ULTERHALTER, 2012; MALET, 2004), trazemos a possibilidade de aprender com a realidade africana e brasileira, tendo em vista o foco em expectativas educacionais comuns: $o$ atendimento às necessidades da internacionalização, da qualidade educacional e do desenvolvimento cultural e econômico dos países. O propósito é discutir a temática a partir do diálogo, entendendo que o discurso com o outro pode contribuir na busca por caminhos reflexivos às nossas experiências vividas. Isso porque, não sendo possível compreender os processos educacionais por fatos simplesmente objetivos, apostamos no discurso como possibilidade de renovar os saberes da área pelas objeções dos outros interlocutores. Ou seja, a ideia é realocar o outro enquanto participante do discurso universal sobre a garantia da qualidade e da avaliação, conciliando as experiências práticas de cada realidade.

Nessa perspectiva, Gomes (2015), recuperando a produção científica sobre a educação comparada, no Brasil, evidenciou o predomínio das comparações com a América Latina, Portugal e África, "acompanhando a política externa brasileira e as linhas de maior cooperação sul-sul” (2015, p. 248). Observou, ainda, que a avaliação externa e internacional, embora latente na agenda científica, foi objeto de escassos estudos. Por isso, consideramos fundamental juntar os pontos da rede de intenções e ações supranacionais para compreender os meandros das reconfigurações das políticas educativas locais. 


\section{Do círculo virtuoso ao círculo vicioso: o Espaço Europeu de ES e os sistemas de}

\section{garantia da qualidade}

O Processo de Bolonha, que responde às iniciativas para a criação do EEES, compatível e comparável entre os sistemas educacionais da Europa, orienta-se por um conjunto de linhas de ação - adoção de um sistema de graus comparável, um sistema de ensino baseado em três ciclos, um sistema de acumulação e transferência de créditos, promoção da mobilidade, promoção da cooperação europeia na certificação da qualidade, promoção da dimensão europeia no ES, a aprendizagem ao longo da vida, envolvimento das instituições e dos estudantes como parceiros, promoção mundial do EEES e desse com a Área Europeia de Investigação - que consiste na promoção da mobilidade e o incremento da competitividade internacional por meio do reconhecimento das qualificações obtidas. Para a concretização dessas linhas de ação, é necessário estabelecer a confiança mútua com a qualidade do ensino. Por esse motivo, os Ministros da Educação dos países signatários, tendo em vista a linha de ação que visa "a promoção da cooperação europeia na certificação da qualidade do ES" (DECLARAÇÃO DE BOLONHA, 1999), propuseram formas para a garantia da qualidade e sistemas de avaliação externa, bem como de acreditação. Assim, são sugeridas duas formas interligadas para a garantia da qualidade: um Sistema Interno de Garantia da Qualidade do Ensino e processos de avaliação, com intuito de acreditação.

Os sistemas de acreditação destinam-se à verificação do cumprimento de um conjunto de requisitos, junto ao curso ou à instituição analisada, considerados necessários pelo referido sistema, para ser atribuído reconhecimento oficial (acreditação). Nesse sentido, os sistemas de avaliação e de acreditação tendem a convergir em seus objetivos e procedimentos, como duas instâncias complementares de um sistema de garantia de qualidade (Quality Assurance).

Cabe-nos destacar que a criação do Sistema interno de Garantia da Qualidade do Ensino, vinculado à tradição europeia da autonomia institucional, propõe que cada instituição promova mecanismos próprios de garantia da qualidade, passíveis de reconhecimento por entidades externas. Assim, os sistemas de certificação devem conciliar a avaliação interna (nacional), a avaliação externa (realizada por países parceiros), a participação dos estudantes e a publicação de resultados. Os diferentes sistemas nacionais devem adotar, ainda, procedimentos comparáveis e quadros comuns de referência no âmbito da Rede Europeia para a Garantia da Qualidade no Ensino Superior (ENQA), criada em 1998, reunindo os principais organismos de acreditação da Europa. 
Compreendendo que a criação do EEES, demanda apoio e supervisão, os Ministros da Educação, a partir da Declaração de Bolonha, assumiram o compromisso de avaliar o seu progresso e decidir sobre novas demandas, na realização de encontros bianuais. Ou seja, a Declaração de Bolonha, que desencadeou o chamado Processo de Bolonha, será acompanhada e complementada pelos Comunicados subsequentes, conforme analisamos, suscintamente, a seguir.

No Communiqué de Prague (2001), os Ministros constataram que os sistemas de garantia de qualidade desempenham um papel decisivo "na garantia de elevados padrões de qualidade e melhoria da comparabilidade de qualificações" e que, por isso, precisam ser ampliados (ERICHSEN, 2007), tendo em vista a atratividade e a competitividade internacional.

No Communiqué of the Berlin (2003), foi ratificado que a qualidade da formação superior é fundamental para a criação do EEES, enfatizando-se a necessidade da elaboração de critérios e métodos reconhecidos de garantia de qualidade. Assim, os processos de avaliação, com intuito de acreditação, comportam dois significados para a garantia da qualidade, conforme o Comunicado de Berlim (2003): a qualidade de um curso ou instituição (avaliação e credenciamento) e a garantia dessa qualidade a terceiros (acreditação). Por isso, os Ministros acordaram que

[...] a partir de 2005, os sistemas nacionais de certificação deverão contemplar: uma definição das responsabilidades de cada uma das instituições envolvidas; a avaliação dos programas ou das instituições, incluindo avaliação interna, avaliação externa, participação dos estudantes e publicação de resultados; um sistema de acreditação, certificação ou procedimentos comparáveis; participação internacional, cooperação e sistemas de redes (Communiqué of the Berlin, 2003, p. 3).

No Comunicado de Bergen (2005), propuseram a adoção de um marco de qualificação mais abrangente para o EEES, prevendo indicadores descritivos com fundamento em resultados de aprendizagem e competências para cada ciclo da formação. "No âmbito da garantia da qualidade, os ministros cobram maiores avanços. Concordam com um 'catálogo de padrões e diretrizes de garantia da qualidade, no Espaço Europeu de Ensino Superior, proposto pela ENQA'” (ERICHSEN, 2007, p. 26).

No Comunicado de Londres (2007), afirma-se a construção do EEES baseado em "autonomia institucional, liberdade acadêmica, igualdade de oportunidades e princípios democráticos que facilitarão a mobilidade, aumentarão a empregabilidade e fortalecerão a atratividade e competitividade da Europa”. Em relação à Certificação de qualidade e Registro europeu das Agências de Qualidade, constatou-se que todos os países signatários realizaram progressos e, ainda, que "[...] la responsabilidad principal respecto a la calidad reside en las propias instituciones de educación superior, éstas deberían continuar fortaleciendo sus sistemas de mejora de la calidad" (2007, p. 3). Também são reconhecidos os avanços no reconhecimento 
mútuo da acreditação e a cooperação internacional entre as agências de certificação da qualidade.

No Communiqué Leuven (1999), os Ministros reconheceram que não conseguiriam completar o projeto de Bolonha e, por isso, é necessário continuar o Processo, com outras metas e prazos. Salientaram que a garantia da qualidade permanecerá como uma prioridade em um contexto que busca fornecer informações sobre as IES. "Decidiram investir na inovação científica e tecnológica para aumentar o nível de competitividade da União no mercado globalizado. A educação superior foi tratada como fator de desenvolvimento e fundamental para atingirem os seus objetivos" (MARQUES; AUGISTÍ, 2012, p. 133).

Na Budapest-Vienna Declaration (2010), os Ministros expressam que a Declaração de Bolonha "estabeleceu uma visão para 2010, de um nível internacional competitivo e atrativo para o Ensino Superior Europeu". Reafirmam a responsabilidade pública com o ES, a importância da mobilidade e do reconhecimento das qualificações, bem como a promoção da aprendizagem centrada no estudante e programas de aprendizagem flexíveis.

A Bucharest Communiqué (2012) reafirmou que a reforma em curso contribuirá com a recuperação da economia europeia, a geração de empregos e o crescimento sustentado. Para tanto, reforça que é necessário uma ES de qualidade, contribuindo com o desenvolvimento de competências que ampliem a empregabilidade dos estudantes e a mobilidade. A garantia de qualidade permanece na agenda como mecanismo de construção de confiança que reforça o carácter atrativo do EEES.

Na Conferência Ministerial realizada em Yerevan, Arménia, em 2015, ratificou-se que a "implementação de reformas estruturais acordadas é um pré-requisito para a consolidação do EEES e, no longo prazo, para o seu sucesso" (YEREVAN COMMUNIQUÉ, 2015, p. 3). São fundamentos dessa reforma a estrutura comum e graus de crédito do sistema, padrões e diretrizes de garantia de qualidade, cooperação para mobilidade e programas conjuntos. Destacou-se que "a implementação integral e coerente das reformas acordadas a nível nacional requer compromisso político e das comunidades acadêmicas e de uma maior participação das partes interessadas" (2015, p. 3), para viabilizar o funcionamento e a credibilidade de todo o EEES, lançado há 16 anos.

Corroborando com esta análise, Lima, Azevedo e Catani (2008, p. 12) concluem que é "visível, com efeito, uma reforma da educação superior à escala europeia, sem precedentes, em que se destaca, em primeiro lugar, uma grande perda de protagonismo dos estados nacionais [...]", uma "europeização" da ES, "optando por políticas de liberalização e pela necessária harmonização para a emulação e a competitividade, vencendo barreiras e fronteiras tradicionais" (LIMA; AZEVEDO; CATANI, 2008, p. 12). Evidencia-se um processo de redução da autonomia 
dos estados-nações e das instituições, em um cenário onde as reformas educativas são organizadas com base nos ordenamentos da qualidade e dos mecanismos de avaliação. Nesse sentido, Dias Sobrinho destaca que a avaliação externa tem sido a "ferramenta principal da organização e implementação das reformas educacionais. Produz mudanças nos currículos, nas metodologias de ensino, nos conceitos e práticas de formação, na gestão, nas estruturas de poder, nos modelos institucionais, nas configurações do sistema educativo" (2010, 195). Desse modo, entre a busca por padrões de qualidade e a atuação dos estados-nações, percebemos que o ES vem sendo orientado por uma cultura, cada vez maior, de padronização.

As Conferências que integram o Processo de Bolonha confirmam a relevância dada à padronização da avaliação, por via do estabelecimento de diretrizes gerais, a partir das quais os vários sistemas nacionais de avaliação devem se adequar, o que, por sua vez sinaliza uma indispensável aproximação dos dispositivos de avaliação interna (nacional). Por essa via, se conforma um campo comum de avaliação fundamentado em critérios e metodologias comparáveis quantitativamente. Impõe-se, nesses termos, a necessidade de ajustamento da avaliação, sem, no entanto, desconsiderar a especificidade do ES de cada um dos países. Como adverte Dias Sobrinho:

[...] não se pode adotar os mesmos critérios, instrumentos e procedimentos para a avaliação de uma grande universidade de pesquisa, de caráter universal, possuidora de laboratórios e de bibliotecas adequados e de docentes de grande capacitação, e para a avaliação de uma instituição regional, carente de infraestrutura para o desenvolvimento da pesquisa, embora possa realizar o seu projeto com forte enraizamento em seu contexto social, portanto com relativa qualidade e pertinência (1997, p. 74).

Significa que a diversidade organizacional e contextual são aspectos a considerar na configuração da avaliação, a partir dos quais se pode perspectivar a abrangência e a especificidade da avaliação. É necessário pensar a avaliação para além de uma única luz objetiva, pois não existindo uma determinação natural de qualidade em educação, os sistemas educativos precisam ser analisados por critérios mais próximos às suas realidades.

\section{Decorrência do Processo de Bolonha para a organização de mecanismos para garantia da qualidade e de avaliação da ES, no âmbito da CPLP}

Nossa análise, no âmbito do Processo de Bolonha, vincula-se às reformas educacionais de quatro países - Angola, Brasil, Cabo Verde e Moçambique - que integram a Comunidade dos Países de Língua Portuguesa (CPLP) e das universidades que fazem parte da Associação das Universidades de Língua Portuguesa (AULP). 
Destacamos que "a ideia de criação de uma comunidade de países e povos que partilham a Língua Portuguesa - nações irmanadas por uma herança histórica, pelo idioma comum e por uma visão compartilhada do desenvolvimento e da democracia - foi sonhada por muitos ao longo dos tempos" (CPLP, 2015, s/p). As mobilizações foram iniciadas em 1983, mas sua criação efetivou-se em Lisboa, em 1996, quando da realização da Cimeira de Chefes de Estado e de Governo. Na ocasião, a CPLP organizou-se por meio da reunião de Angola, Brasil, Cabo Verde, Guiné-Bissau, Moçambique, Portugal e São Tomé e Príncipe. Em 2002, com a independência, agregou-se Timor-Leste e em 2014, a Guiné Equatorial, como nono país da Comunidade. A CPLP "é o foro multilateral privilegiado para o aprofundamento da amizade mútua e da cooperação entre os seus membros", orientado pelos seguintes objetivos gerais:

A concertação político-diplomática entre seus estados membros, nomeadamente para o reforço da sua presença no cenário internacional; A cooperação em todos os domínios, inclusive os da educação, saúde, ciência e tecnologia, defesa, agricultura, administração pública, comunicações, justiça, segurança pública, cultura, desporto e comunicação social; A materialização de projectos de promoção e difusão da língua portuguesa (CPLP, 2015, não paginado).

No âmbito educacional, a Comunidade reconhece a necessidade de uma visão mais aberta, intercultural, dos sistemas de educação e de ensino. Alinha-se às ações de mobilidade, também presentes no Processo de Bolonha, como a "realização de intercâmbios e uma maior mobilidade de investigadores, docentes e estudantes no espaço da Comunidade, visando diversificar e enriquecer o processo de formação dos estudantes" (ROMUALDO, 2007, p. 105), vinculando-se aos desafios decorrentes da globalização e da regionalização.

Nesse sentido, destacaremos alguns objetivos apresentados na Declaração de Fortaleza (2004), Declaração dos Ministros Responsáveis pelo Ensino Superior da Comunidade dos Países de Língua Portuguesa (CPLP), que convergem com o Processo de Bolonha e, posteriormente, discutiremos a criação dos sistemas de avaliação e de garantia da qualidade em Angola, Brasil, Cabo Verde e Moçambique.

Com os objetivos de "estimular a cooperação em matéria de ensino superior que permita valorizar a formação conferida pelas instituições de ensino superior da CPLP, aprimorar sua qualidade e o reconhecimento das qualificações, quer no âmbito da CPLP, quer noutros espaços internacionais" e de " reforçar a posição internacional da formação de nível superior em língua portuguesa e a promover a mobilidade no espaço da CPLP”, os Ministros da Comunidade dos Países de Língua Portuguesa (CPLP), responsáveis pelo ensino superior, renovaram o apoio à cooperação e propuseram construir, nos próximos dez anos, um Espaço de Ensino Superior da CPLP, indicando como prioridades, o "estímulo à qualidade das for- 
mações oferecidas no âmbito da CPLP e ao reconhecimento mútuo e internacional; a promoção da mobilidade de estudantes, docentes, investigadores e técnicos; a cooperação no domínio da estrutura das formações superiores", entre outras. Os Ministros também destacam que a construção do Espaço de Ensino Superior da CPLP, demanda a colaboração das instituições e da Associação das Universidades de Língua Portuguesa. Observa-se, portanto, que a preocupação com a qualidade das formações e com o reconhecimento mútuo e internacional está na pauta não só dos países signatários do Processo de Bolonha, mas, também, no âmbito da CPLP.

Nesse contexto, a consolidação do ensino superior em Angola é vista como um fator para a garantia da qualidade da formação, sendo reconhecida a necessidade de um maior investimento na melhoria da qualidade da prestação das instituições educativas integradas no subsistema de ES. As políticas educativas têm sido objeto de reformulação, fazendo parte de projetos legislativos que visam à melhoria da qualidade do desempenho do ensino superior. Nesse processo, particular atenção tem sido conferida à avaliação, resumindo-se, por agora, na procura de estruturas e mecanismos institucionais, incluindo dispositivos legais que possam dar corpo a um sistema nacional, que se pretende estruturante, para a promoção e a garantia da qualidade.

Entre os documentos que constituem "indicativos obrigatórios" para a abordagem de matérias relacionadas com as instituições educativas em Angola, há que se referenciar a Lei de bases do Sistema Educativo angolano (LBSE), o Plano Nacional de Formação de Quadros (PNFQ) e a Estratégia Nacional para a Formação de Quadros (ENFQ), cuja validade se aplica à abordagem da avaliação no contexto do ensino superior. Relativamente à avaliação, tratam-se de referenciais genéricos, sem a indicação de elementos específicos relacionados com a sua estruturação e a sua operacionalização.

As linhas mestras para a melhoria da gestão do subsistema de ES em Angola e o respetivo Plano de implementação podem ser considerados como os elementos mais estruturantes no âmbito das políticas educativas que visam à melhoria da qualidade do ensino superior, em geral, e das instituições e cursos desse nível, em particular. Para dar corpo e operacionalizar essa intenção, foi recentemente criado o Instituto Nacional de Avaliação, Acreditação e Reconhecimento de Estudos do Ensino Superior ${ }^{1}$ (Inaarees), cuja missão consiste em promover e monitorar a qualidade das instituições de ensino superior.

Verifica-se que há intenção de se configurar um quadro avaliativo de natureza abrangente, pois, as ações de monitoria da qualidade apresentam subjacente uma lógica que incorpora as dimensões pedagógica e científica, a prestação de serviços à comunidade por parte das instituições educativas, bem como a organização e a ges- 
tão organizacional. Ao prever-se a "verificação das condições técnico-pedagógicas e científicas para a criação de instituições de ensino superior", o estabelecimento de "critérios de avaliação, de modo a obter a tradução dos seus resultados em apreciações qualitativas", o estabelecimento de um "quadro classificatório das instituições de ensino superior e cursos a nível nacional, em função dos resultados de avaliação obtidos" (alíneas d, g, n - artigo 6º , DP n.․ 172/13, de 29 de outubro), fica evidente a tendência de se configurar um sistema de avaliação que se venha a orientar por perspectivas qualitativas e quantitativas, subsumidos na pretensão de criação de um quadro classificatório das IES.

O PNFQ (ANGOLA, 2012), no qual são identificáveis um conjunto de elementos que reportam a avaliação como um mecanismo para a melhoria da qualidade do ensino superior, prevê a realização da avaliação em dois ciclos: (i) primeiro ciclo de avaliação: cuja implementação deveria ocorrer a partir de 2014, com uma abordagem pedagógica, de trabalho com as instituições no sentido de identificar as ações necessárias à melhoria da qualidade do ensino superior; (ii) uma fase posterior, a ser realizada após a primeira ronda completa de avaliação, subentende-se do primeiro ciclo, em que os resultados da avaliação poderão ter consequências, entre as quais o licenciamento de cursos e de instituições. Ou seja, a ausência e/ou insuficiência de normativos legais e as mudanças operadas no subsistema do ensino superior são os fatores externos mais referenciados como obstáculos à dinamização da avaliação.

Nesse quadro, importa referir que o Estado tem considerável protagonismo no estabelecimento de um sistema nacional de avaliação do ensino superior em Angola, tal como acontece em outros contextos educativos. Freitas (2012), num estudo que visou comparar os sistemas de avaliação da educação superior do Brasil e de Portugal concluiu que, nesses países, a avaliação entendida como sistema não é uma atividade voluntária e sim uma política de Estado, por meio da qual são estabelecidas etapas e padrões mínimos de referência, configurados como indicadores obrigatórios a serem observados pelas instituições. Trata-se, em essência, de assegurar, o que, no âmbito da declaração de Bolonha constituem critérios e metodologias que sejam passíveis de comparação numa perspectiva determinista. Para Lima, seria uma questão de se salvaguardar a "convergência sistémica", vista como

[...] um sistema normativo baseado em normas injuntivas detalhadas e padronizadas, que visam produzir um certo isomorfismo estrutural e morfológico entre distintas unidades, práticas ou objetos a avaliar, integrando uma certa diversidade de casos ou objetos, embora reconhecíveis e aceites pelo sistema, independentemente do seu número e da sua localização (2011, p. 76). 
A questão da qualidade do ensino superior em Angola, faz parte da abordagem de acadêmicos, gestores educacionais, sendo também matéria referenciada no plano das políticas educativas.

Inicialmente, uma análise circunscrita a alguns eventos associados ao ensino superior em Angola torna evidente que, tal como em outros contextos, a massificação da educação implícita na nacionalização e na democratização, decorrente de um momento histórico particular vivenciado (Independência Nacional), teve como consequência a explosão do efetivo estudantil. Na prática, esse aumento quantitativo não foi acompanhado pelo correspondente aumento qualitativo, do que resultou desequilíbrios consideráveis dos diversos dispositivos que conformam o sistema educativo, colocando em causa a qualidade da formação prestada. A este respeito a (ex)Ministra de tutela, no seu discurso de abertura do ano académico 2011, pronunciou-se nos seguintes termos:

Um olhar atento à nossa realidade interna, permite-nos dar conta de que continuamos a registar uma grande carência de quadros técnicos qualificados, no que se refere quer aos sectores económicos e sociais quer fundamentalmente aos sectores emergentes, onde o conhecimento científico e tecnológico e assim como as tecnologias de ponta fazem a diferença em termos de know how (MESCT, 2011, p. 6, grifo nosso).

Essas reflexões indiciam um quadro em que a quantificação nem sempre encontra conexão com a evolução dos demais dispositivos educativos, especialmente 0 corpo docente, materiais pedagógicos, infraestrutura e recursos financeiros, do que resultam desequilíbrios estruturais e funcionais e, consequentemente, a desconexão quantidade/qualidade.

Em Angola, a qualidade tem figurado o centro das abordagens e dos espaços institucionais de reflexão e de discussão sobre a gestão do ensino superior. Tais são esses espaços institucionais: a) Primeiro Seminário Inter-regional sobre Avaliação e Acreditação das IES, do qual participaram gestores das IES, com o objetivo central de "sensibilizar os diversos actores do Ensino Superior sobre a pertinência e a relevância da avaliação e acreditação, como processos que visam à promoção e a garantia da qualidade das IES" (CI-INAAES, 2011). b) Conselho Consultivo do Ministério do Ensino Superior Ciência e Tecnologia (MESCT), realizado sob o lema "juntos, pela promoção da qualidade dos serviços, da formação superior e da investigação científica". Nesse Conselho, foi incluído o tema "Os Desafios da Gestão e da Qualidade do Ensino Superior em Angola”, em cuja abordagem foi reiterada a fraca funcionalidade das IES, resultante da distorção na compreensão de determinados conceitos, de insuficiências e desarticulações dos vários dispositivos educativos e de manifestações de resistência associadas a interesses especulativos 
(NASCIMENTO, 2012). c) Primeira Conferência Nacional sobre o Ensino Superior, que incluiu o painel "Garantia da Qualidade no Ensino Superior".

Esses eventos revelam a centralidade e a valorização que o termo qualidade adquire no contexto educativo angolano, o que, no entanto, até ao momento, não se tem revelado suficiente para a formalização e a concretização de mecanismos de garantia da qualidade, como foi referido. Mantem-se apenas em projeto a configuração de um sistema de avaliação do subsistema de ES e respetivos órgãos dependentes.

A criação de estruturas encarregadas pela avaliação também é um aspecto referenciado perspectivando-se a realização da avaliação em duas dimensões: interna e externa, sendo considerada a possibilidade e a estruturação de um sistema nacional de avaliação que venha a ser articulado com sistemas específicos de cada uma das IES (Resolução n.․ 4/07, de 2 de fevereiro, linha mestra, alínea aa). Trata-se de uma agência nacional de avaliação e de instâncias locais de avaliação ao nível das universidades (comissões de avaliação).

Relativamente aos indicadores, a avaliação assume, tendencialmente, caráter multidimensional, já que todos os dispositivos educativos constituem-se em objeto de avaliação, expressamente, "a finalidade da instituição, os perfis de saída, os currículos, o corpo docente, o corpo discente, os recursos financeiros, os recursos materiais, os recursos humanos, o processo de ensino-aprendizagem, a investigação científica, a organização e gestão" (Resolução n. ${ }^{\circ}$ 4/07, de 2 de fevereiro, alínea aa).

No Brasil, por sua vez, a avaliação das instituições de educação superior e dos cursos de graduação foi organizada a partir da década de 1990, e ampliada com a aprovação da Lei N. 10.861 , de 14 de abril de 2004, que instituiu o Sistema Nacional de Avaliação da Educação Superior - Sinaes, atribuindo à Comissão Nacional de Avaliação da Educação Superior (Conaes) a coordenação e supervisão do Sinaes, com a competência de definir diretrizes, critérios e estratégias para tal empreendimento. "A proposição desse sistema teve por objetivo construir um sistema nacional de avaliação que articulasse a regulação e a avaliação educativa, esta última numa perspectiva mais formativa e voltada para a atribuição de juízos de valor e mérito" (PEIXOTO, 2011, p. 14), contemplando a participação dos agentes educativos e as dimensões interna e externa no processo de avaliação.

Dias Sobrinho (2010) explica que, na visão do Sinaes, a articulação entre regulação e avaliação seria contemplada por um conjunto integrado de instrumentos de avaliação - avaliação institucional (autoavaliação e avaliação externa), avaliação dos cursos de graduação e avaliação de desempenho dos estudantes (Enade) - produzindo informações para as ações regulatórias do Conselho Nacional de Educação e do Ministério da Educação, que expressam as prerrogativas do Estado no que 
concerne ao credenciamento e ao recredenciamento das instituições, à autorização e ao reconhecimento dos cursos; e à avaliação formativa que, destacada por Peixoto (2011), conta com a participação da comunidade acadêmica. Conforme afirma Dias Sobrinho (2010, p. 208), “com base nos resultados globais da avaliação, e não em um único instrumento, a regulação seria mais confiável, fundamentada e eficaz do ponto de vista da relevância social e da pertinência essenciais à construção da qualidade do sistema de educação superior" (2010, p. 208).

No entanto, mais recentemente, os resultados da avaliação vem expressando uma forte tendência para o ranking dos cursos e das instituições, principalmente a partir da Portaria Normativa n.. 12/2008, do Ministério da Educação que instituiu o "Índice Geral de Cursos da Instituição de Educação Superior (IGC) e consolida informações relativas aos cursos superiores constantes dos cadastros, do censo e das avaliações oficiais disponíveis no Instituto Nacional de Estudos e Pesquisas Anísio Teixeira (Inep) e na Coordenação de Aperfeiçoamento de Pessoal de Nível Superior (Capes)" (BRASIL, 2008, p. 1). Ou seja, ao realizar-se uma fusão de indicadores da graduação e da pós-graduação, os resultados têm fortalecido ações de comparação e de classificação entre as instituições.

Para Dias Sobrinho (2010, p. 2010), "na concepção original do Sinaes, a educação transcende o desempenho estudantil em provas estáticas, [...] buscando significados amplos da formação humana integral e pondo em questão a responsabilidade social das IES". No entanto, muitas dificuldades foram encontradas na implantação desse sistema: a inexistência de uma cultura institucional de avaliação processual e formativa; as dificuldades em criar uma cultura de participação nas instituições; a não adesão, em um primeiro momento, de instituições municipais e estaduais de educação superior e a falta de balizadores para o desenvolvimento das IES, tais como o Plano de Desenvolvimento Institucional (PDI); a composição do banco de avaliadores externos, que nem sempre são selecionados conforme critérios sugeridos nos regulamentos, entre outros aspectos. Dias Sobrinho considera que, apesar das dificuldades, o período inicial de implantação “[...] não se limitava à conformação a normas burocrático-legais. Entretanto, as recentes iniciativas do Inep, com o aval do Conaes, tendem a interromper esse processo participativo e retomar ao paradigma técnico-burocrático" (2010, p. 215).

A avaliação externa das IES, conforme o Sinaes, constitui-se por meio de bases de informação quantitativa, informada pelas IES, referente à infraestrutura física, a recursos humanos, Cadastro e Censo da Educação Superior e avaliações já realizadas pelo MEC; e qualitativas, decorrentes da análise das informações quantitativas e das comparações entre o que a IES propõe e suas capacidades, a partir das interações entre os avaliadores e os agentes educativos. As informações qua- 
litativas vinculam-se diretamente ao cotejamento entre as concepções expressas no Projeto Pedagógico Institucional (PPI), as metas do Plano de Desenvolvimento Institucional (PDI) e o nível de realização alcançado pela IES com o objetivo de captar as dinâmicas institucionais na direção da qualidade.

Em Moçambique, o Ensino Superior remonta do longínquo ano de 1962, quando foi aberta a primeira instituição designada então Estudos Gerais Universitários de Lourenço Marques. Este fato acontecia ao abrigo do Decreto-lei no 44.530 e marcava a criação do que, mais tarde, após a Independência do País, em 1975, chamar-se-ia de Universidade Eduardo Mondlane-UEM.

Depois da independência do país e com a revisão da Constituição da República, em 1990, Moçambique se abriu para a economia de mercado e criou, em 1993, a primeira Lei sobre o ensino superior: a Lei n..$^{\circ}$ 1/93, tendo como decorrência 0 surgimento de muitas iniciativas de investimento nesse nível e a abertura de muitas Instituições de Ensino Superior. Como resultado, o governo criou, em 2000, o Ministério do Ensino Superior, Ciência e Tecnologia, o qual, por sua vez, implementaria o primeiro Plano Estratégico do Ensino Superior, por um período de 10 anos (2000 - 2010), implicando em acordo financeiro com o Banco Mundial. A implementação do chamado Projeto do Ensino Superior (PES) resultou (i) na reforma e desenvolvimento de todo o subsistema do ensino superior, (ii) no desenvolvimento e investimentos institucionais - uma fase em que o $\mathrm{QIF}^{2}$ se destacou como o programa financiador das instituições de ensino superior - e (iii) no programa de bolsas oferecidas pelo Governo às províncias (MINED, 2010).

O principal objetivo do Plano Estratégico era institucionalizar um Sistema do Ensino superior diversificado, flexível e integrado com uma eficiência econômica que contribuísse para o desenvolvimento do país. Os objetivos do plano incluiam, também, a formação de recursos humanos em nível superior, com conhecimentos e competências apropriadas, relevantes e flexíveis e capazes de responder às necessidades sociais de um mercado de trabalho em constante mudança.

A partir dos anos 2009/10, e com a consequente necessidade de harmonizar o sistema e controlar aspectos de qualidade, o governo aprovou a Lei $n^{\circ} 5 / 2003$, visando à garantia da Qualidade no Ensino Superior. É assim que, em 2009 é criada a atual Lei do Ensino Superior em Moçambique de nº 27/2009, na qual o Ensino Superior passa a ser desenvolvido e observado uma série de Normas de Funcionamento que buscam eficácia e eficiência desse subsistema. Dessas normas, importa, para os propósitos desse artigo, destacar a atividade e o impacto do Sistema Nacional de Avaliação, Acreditação e Garantia de Qualidade do Ensino Superior (Sinaqes), pois se volta para a avaliação externa do ensino superior.

O Sinaqes é um sistema que integra normas, mecanismos e procedimentos coerentes e articulados que visam concretizar os objetivos da qualidade do ensino 
superior (Conselho de Ministros, 2007). De acordo com o Boletim da República Número 52, I Série, esse sistema compreende três subsistemas: a autoavaliação, a avaliação externa e a acreditação (Art. 4). Dentre as atribuições do Sinaqes importa destacar (i) a identificação, o desenvolvimento e a implementação de normas e indicadores de qualidade, (ii) a informação à sociedade sobre a qualidade de ensino nas instituições de ensino superior e (iii) o apoio na identificação de problemas do ensino superior, o esboço de mecanismos da sa resolução e a definição das políticas do Estado para o setor. Para a implementação do Sinaqes, foi criado o Conselho Nacional de Avaliação de Qualidade do Ensino Superior (CNAQ) que, sob tutela do Ministro que superintende o Ensino Superior, desempenha funções específicas, deliberativas e reguladoras em matéria de avaliação e acreditação das instituições de ensino superior na defesa do interesse público (Art.5).

Essa avaliação do CNAQ, que é naturalmente externa às instituições de ensino superior, visa realizar-se um juízo independente de aferição dos vários indicadores de qualidade considerados no exercício de autoavaliação (a avaliação interna das instituições), bem como no fornecimento de garantias às instituições, parceiros e ao CNAQ do cumprimento da missão e visão institucionais (MINED, 2012).

Globalmente, a avaliação externa incide sobre a qualidade das instituições, mais concretamente sobre os sistemas, políticas, planos estratégicos, recursos e regulamentos que garantam uma gestão e uma administração de qualidade dos principais pilares de ensino-aprendizagem, investigação e extensão. Isso sugere que essa avaliação reflete igualmente nas questões de gestão e de financiamento institucionais, em termos do seu impacto no alcance dos objetivos estratégicos.

De um modo geral, o desafio do Ensino Superior, hoje em Moçambique, é como garantir a qualidade do Sistema como resposta ao necessário controle da expansão ocorrida na década de 2000 a 2010. Esse desafio é consubstanciado pela frágil capacidade de o governo mobilizar e potencializar o desempenho das escolas tecnico-profissionais e vocacionais para o ensino terciário de forma a responderem à demanda das atuais necessidades de um mercado de trabalho cada vez mais voltado para a exploração de recursos naturais do país. Isso está aliado não só à concorrência exercida pela economia de mercado ${ }^{3}$ como à aparente desarticulação entre as instituições de ensino superior públicas na abordagem das necessidades do mercado de trabalho.

Em Cabo Verde, o ensino superior teve início após a independência, vinculado aos planos de desenvolvimento do país (CARDOSO, 2014). O primeiro estabelecimento desse nível foi decorrente da organização do Curso de Formação de Professores do Ensino Secundário, em 1979 (Decreto n. 70/1979). Conforme destaca Varela, "o modelo cabo-verdiano segue, de perto, o português, com poucas nuances" (2013. p. 5). 
Atualmente, o ensino superior compreende o ensino universitário e o ensino politécnico, formado por nove instituições (1 pública e 8 privadas). Cabe-nos salientar que o "[...] Ensino Superior privado acolhe a maioria dos estudantes universitários, constituindo por isso um bem nacional importante, e que o governo pode tomar medidas adequadas de interesse nacional para o seu desenvolvimento" (BANCO MUNDIAL, 2012, p. 9). É nesse contexto de ampliação da oferta e do número de IES que surge, em 2011, o projeto Garantia da Qualidade: criação do sistema de avaliação do ensino superior em Cabo Verde, no âmbito da cooperação Brasil-África. O projeto envolve a parceria entre o Instituto Nacional de Estudos e Pesquisas Educacionais Anísio Teixeira (Inep), o Ministério do Ensino Superior, Ciência e Inovação (Mesci) de Cabo Verde, por meio da Direção-Geral do Ensino Superior (DGES) e o apoio da Agência Brasileira de Cooperação (ABC) (BRITO, 2013).

Brito (2013) informa que foram realizados seminários, com a participação dos docentes, gestores das instituições de ensino superior de Cabo Verde, técnicos do Mesci e da equipe de apoio e orientação do Inep, para a construção dos indicadores e dos instrumentos de avaliação. Nesse processo, foram definidas cinco dimensões institucionais a avaliar: a) o Plano Estratégico de Desenvolvimento Institucional e autoavaliação; b) gestão institucional; c) infraestrutura; d) política acadêmica; e e) política de pessoal. A avaliação externa também é subsidiada pelo relatório de autoavaliação das IES e dos resultados da avaliação in loco das comissões de avaliação, que possuem como base os critérios descritos no Guião de Avaliação (MESCI, 2014a).

Nas Diretivas do Sistema Nacional de Garantia da Qualidade do Ensino Superior (Sinaqes), evidencia-se que a aposta na qualidade de desempenho das instituições vincula-se às políticas e aos normativos definidos pelo Estado, com ênfase nos processos de regulação do sistema, de acreditação e avaliação das instituições e dos cursos, com a interligação dos sistemas de autoavaliação e de heteroavaliação. A concepção do Sistema estruturou-se em torno da visão estratégica da qualidade, entendida e aferida numa perspectiva multifatorial e multidimensional, tendo como referenciais a legislação educacional, as diretivas institucionais do Estado, os estatutos e planos estratégicos das instituições, cuja observância é espelhada nos instrumentos de avaliação e de monitoramento das instituições e dos cursos. "O SNAQES compreende a avaliação institucional interna e externa das instituições e cursos, devendo garantir o caráter público e transparente de todos os procedimentos, dados e resultados dos processos avaliativos [...]" (MESCI, 2014b, p. 5).

Constata-se, portanto, que os processos de avaliação e de garantia da qualidade da educação superior em Angola, Brasil, Moçambique e Cabo Verde, decorre das ações dos Estados, fortemente influenciada por uma agenda internacional, em um cenário de expansão e de diversificação de modelos institucionais de ES. 


\section{Avaliação e qualidade}

Independente do modelo ou da configuração, conforme observamos, os diversos países vêm organizando sistemas de avaliação externa das instituições de educação superior com a intenção de acreditação, qualificação e accountability. A avaliação externa tem sido a "ferramenta principal da organização e implementação das reformas educacionais. Produz mudanças nos currículos, nas metodologias de ensino, nos conceitos e práticas de formação, na gestão, nas estruturas de poder, nos modelos institucionais, nas configurações do sistema educativo [...]" (DIAS SOBRINHO, 2010, p. 195).

Entretanto, apesar dos esforços, os sistemas nacionais de avaliação têm apresentado dificuldades em identificar os indicadores qualitativos, o conceito de qualidade e os processos para sua realização (BERTOLIN, 2009). A polissemia de entendimentos sobre a qualidade da educação não confere universalidade ao conceito. Bertolin (2009) sugere a predominância de três tendências: a) a economicista, vinculada ao crescimento da economia, empregabilidade e eficiência; b) a pluralista, voltada ao desenvolvimento econômico, cultural, social e democrático, considerando a diferenciação, pertinência e participação; e c) a equidade, orientada para a promoção da igualdade de oportunidades e coesão social.

Morosini e Franco (2012) também analisaram as abordagens de qualidade presente nas políticas e nas estratégias nacionais, vinculadas à educação superior, e identificaram: a) a abordagem técnica de qualidade, voltada para identificação de resultados e consequente classificação e comparabilidade objetiva entre cursos e instituições; e b) a abordagem de qualidade social, vinculada à expansão do acesso, inclusão e inserção social.

Morosini (2014) também identificou, a partir do estudo do estado do conhecimento internacional, a noção de qualidade vinculada a três tipos: a qualidade isomórfica, modelo único visando padrão acadêmico de competência organizacional e de serviços, em que a acreditação é mais valorada do que a avaliação e, por isso, potencializa a elaboração dos rankings; a qualidade da especificidade, que se vincula à presença de indicadores estandardizados paralelos à preservação do específico, na crença e no reconhecimento dos mecanismos avaliativos de cada país; e a qualidade da equidade que se vincula à concepção de tratamento diferenciado para quem é diferenciado, visando o compromisso social e o reconhecimento da diversidade.

Apesar da polissemia de entendimentos, de indicadores e de processos envolvidos na definição da qualidade educacional, os programas e as políticas de avaliação, talvez, constituam o mecanismo mais eficiente para sua regulação e para a reestruturação do papel do Estado em matéria educacional, conforme observamos 
na organização dos sistemas de avaliação em Angola, Brasil, Moçambique e Cabo Verde. As políticas de avaliação externas são necessárias para o equilíbrio na qualidade do ensino superior, no entanto, é preciso ficar alerta para que essas avaliações não gerem fenômenos regressivos de retraimento das identidades, definindo qualidade por meio de números.

\section{Considerações finais}

As instituições de educação superior, nos últimos anos, vêm passando por muitas mudanças (expansão e diversificação, internacionalização, etc.) e, parte dessas, decorrentes das ações interventivas dos Estados no cenário nacional e internacional. A partir dos anos 1990, verifica-se uma pressão para que os Estados ampliem seus índices de produtividade e de desempenho nos sistemas de ensino como forma de capital cultural e de fonte para a concorrência econômica internacional. É nesse cenário que se estruturam os sistemas nacionais de garantia da qualidade e de avaliação nos países em estudo.

A determinação de procedimentos comparáveis e de quadros comuns de referência, ao que se acrescenta a criação de instâncias internacionais de avaliação da educação superior, pode induzir a variantes avaliativas fortemente influenciadas por agentes externos, dada a localização da fonte da iniciativa. Assim, podemos entender que, no campo da análise organizacional centrada nas relações entre a organização, nesse caso o ensino superior, e o ambiente, estaríamos em presença do isomorfismo (DIMAGGIO; POWELL, 1999), o que permite estabelecer traços da interioridade e da exterioridade avaliativa. Nesse caso, as avaliações induzidas por pressões externas, particularmente as de natureza imposta, colocam a universidade em situações que a obrigam a submeter-se às pressões das instâncias internacionais para acionar e adaptar os seus sistemas de avaliação, o que se enquadra nas caraterísticas do isomorfismo coercivo. Considera-se, assim que estaríamos em presença de uma avaliação de natureza padronizada que se define por um conceito de qualidade sustentado por políticas de governança e não por preocupações científicas.

Esses pressupostos indiciam um quadro de harmonização dos sistemas de avaliação, embora, como referem Lima, Azevedo, Catani, se "recuse a ideia de simples homogeneização ou padronização, eventualmente menos aceitável face à grande diversidade da educação superior nos países aderentes” (2008, p. 10).

A avaliação vem sendo utilizada para orientar as políticas públicas no setor e garantir o sucesso das instituições diante das necessidades do desenvolvimento do sistema mundial guiado pela lógica do mercado. A universidade está sendo avaliada pelo critério do impacto na vida econômica e social, pela produção de conhecimento 
útil e pela forma de administração instrumental aprendida com o processo de Bolonha. Trata-se de um fato que tem minimizado a autonomia das universidades que, empenhadas no atendimento de critérios objetivos, têm se transformando em espaços de gerenciamento numérico em detrimento da produção humana e acadêmica. Sem controle do seu destino, a universidade tem seguido a lógica da "qualificação" como estratégia de conseguir recursos e participação nas deliberações públicas. Desse modo, entre a busca por padrões de qualidade e a atuação do Estado, percebemos, nos países em estudo, a simplificação do papel da universidade, o que entendemos que poderá levar à extinção do compromisso com a qualidade acadêmica.

\section{Quality assurance and evaluation: a comparative study on the derivations from the Bologna process in community of portuguese language countries}

\section{Abstract}

Higher education in the knowledge society of the twenty-first century has been the object of multiple interests that increasingly put mechanisms for quality assurance on the political agenda. Therefore, a growing number of countries and institutions, encouraged by Conferences, Declarations and Global releases, related to higher education, have come to define an agenda for the reorganization of the curriculum of the courses and the organization of internal and external systems of institutional evaluation, inter alia. Set in this context, this study aims to analyze and discuss the inductions resulting from the Bologna Process, to the organization of mechanisms for quality assurance and evaluation of higher education within the Community of Portuguese Language Countries (CPLP), more specifically, Brazil, Angola, Mozambique and Cape Verde. We consider it essential to join the network points of intentions and supranational actions to understand the intricacies of the reconfigurations of global educational policies. We conclude that the assessment has established itself as an instrument for regulating the quality of Higher Education Institutions and management of the educational agenda of the states. Therefore, it is understood that the creation of evaluation systems is linked to the need for regulation of the states and the induction of the quality of educational systems, in a scenario of diversification of institutional models, and of expansion of access to higher education and integration in addition to international recognition.

Keywords: Evaluation. Quality. Bologna process. Higher education.

\section{Notas}

1 Estruturas antecedentes: Gabinete de Avaliação e Acreditação (Decreto-Lei n.․ 2/2009, de 29 de abril); Instituto Nacional de Avaliação e Acreditação do Ensino Superior (Decreto Presidencial n.. 70/2010, de 19 de maio).

2 QIF - do Inglês Quality and Innovation Fund.

3 Numa decisão bastante contestada, o Governo tem estado a buscar uma comparticipação do sector privado para o financiamento das escolas tecnico-profissionais. 


\section{Referências}

ANGOLA. Ministério do Ensino Superior. Plano Nacional de Formação de Quadros (PNFQ). Luanda, 2012.

BANCO MUNDIAL. Construindo o Futuro: Como é que o Ensino Superior Pode Contribuir Para a Agenda de Transformação Económica e Social de Cabo Verde. Documento do Banco Mundial, 2012. Disponível em <http://www.dgesc.gov.cv/index.php/es/estudos-sobre-es-de-cv/finish/11/19>. Acesso em: 3 abr. 2015.

BERTOLIN, Júlio. Qualidade em educação superior: da diversidade de concepções à inexorável subjetividade conceitual. Avaliação, Campinas; Sorocaba, v. 14 n. 1, p. 127-149, mar. 2009.

Lei n. 10.861, de 14 de abril de 2004. Institui o Sistema Nacional de Avaliação da Educação Superior - Sinaes e dá outras providências. D.O.U. de 15.4.2004.

Portaria Normativa $n^{\circ} 12$, de 5 de setembro de 2008. Institui o Índice Geral de Cursos da Instituição de Educação Superior (IGC). Disponível em: <http://download.inep.gov.br/download/superior/condicoesdeensino/PORTARIA_NORMATIVA_12.pdf>. Acesso em: 12 jan. 2015.

BRITO, Arnaldo Jorge. Desafio da criação do sistema de avaliação do ensino superior em Cabo Verde. Fórum da Gestão do Ensino Superior nos Países e Regiões de Língua Portuguesa. Pernambuco, 2013.

BROCK, Colin. Raízes históricas e sociais de regulamentação e credenciamento da educação superior para garantia de qualidade. In: GUNI - Global University Network for Innovation. Educação superior em um tempo de transformação: novas dinâmicas para a responsabilidade social / trad. Vera Muller. Porto Alegre: Edipucrs, 2009.

BUCHAREST COMMUNIQUÉ. Making the Most of Our Potential: Consolidating the European Higher Education Area Bucharest Communiqué, 2012.

BUDAPEST-VIENNA DECLARATION. Budapest-Vienna Declaration on the European Higher Education Area. March 12, 2010.

CABO VERDE. Ministério do Ensino Superior, Ciência e Inovação (MESCI). Direção-Geral de Ensino Superior. Portaria xx 2014a. Aprova os instrumentos de avaliação institucional externa das Instituições de Ensino Superior. Disponível em: < http://www.dgesc.gov.cv/index.php/ensinosuperior-de-cv/legislacao/finish/10/936>. Acesso em 5 de fevereiro de 2015.

Lei $n^{\circ} 103 /$ III / 1990, de 29 de Dezembro - Aprova as Bases do Sistema Educativo de Cabo Verde (LBSE). Disponível em: <https://portoncv.gov.cv/>. Acesso em: 5 fev. 2015.

. Ministério do Ensino Superior, Ciência e Inovação (MESCI). Direção-Geral de Ensino Superior. Portaria $x x$ 2014a. Aprova os instrumentos de avaliação institucional externa das Instituições de Ensino Superior. Disponível em: <http://www.dgesc.gov.cv/>. Acesso em: 5 fev. 2015.

. Ministério do Ensino Superior, Ciência e Inovação (MESCI). Direção-Geral de Ensino Superior. Despacho n. 27/2014b. Regulamento de Avaliação do Ensino Superior Cabo-Verdiano. Disponível em: <http://www.dgesc.gov.cv>. Acesso em: 5 fev. 2015.

. Decreto $n^{\circ}$ 70 / 79, de 28 de Julho de 1979 - Cria o Curso de Formação de Professores do Ensino Secundário. Cabo Verde, 1979. 
CARDOSO, António Pedro Barbosa. Criação do Sistema Nacional de Avaliação Institucional do Ensino Superior em Cabo Verde. In: ANPED SUL, 10, 2014, Florianópolis. Anais... Florianópolis, 2014.

COMMUNIQUÉ LEUVEN AND LOUVAIN-LA-NEUVE. Communiqué of the Conference of European Ministers Responsible for Higher Education, Leuven and Louvain-la-Neuve, 28-29 April 2009.

COMMUNIQUÉ OF THE BERLIN. Communiqué of the Conference of Ministers responsible for Higher Education in Berlin on 19 September 2003.

COMMUNIQUÉ OF THE PRAGUE. Communiqué of the meeting of European Ministers in charge of Higher Education in Prague, on May 192001.

COMUNICADO DE BERGEN. Comunicado de la Conferencia de Ministros Europeos responsables de Educación Superior. Bergen, 19-20 de Mayo de 2005.

COMUNICADO DE LONDRES. Hacia el Espacio Europeo de Educación Superior: respondiendo a los retos de un mundo globalizado. 18 de mayo de 2007.

CONSELHO DE MINISTROS. Boletim da República, I Série, Número 52, de 31 de Dezembro de 2007. Maputo: Moçambique, 2007.

COWEN, Robert; KAZAMIAS, Andreas M.; ULTERHALTER, Elaine. (Org.) Educação compara$d a$ : panorama internacional e perspectivas. v.1. Brasília: Capes/ Unesco. 2012.

CPLP. Comunidade dos Países de Língua Portuguesa. Disponível em: <http://www.cplp.org/>. Acesso em: 12 jul. 2015.

DECLARAÇÃO DE BOLONHA. Declaração conjunta dos ministros da educação europeus, assinada em Bolonha. Bolonha, 19 de junho de 1999.

DECLARAÇÃO DE FORTALEZA. Declaração dos Ministros responsáveis pelo ensino superior da Comunidade dos Países de Língua Portuguesa. Fortaleza, 26 de maio de 2004.

DIAS SOBRINHO, J. Conceções de Universidade e Avaliação Institucional. In H. Trindade (Org.) Universidade em Ruínas: na república dos professores. Petrópolis: Vozes/Rio Grande do Sul: CIPEDES, p. 149-169, 1999.

. Avaliação e transformações da educação superior brasileira (1995-2009): do PROVÃO ao SINAES. Avaliação, Campinas; Sorocaba, SP, v. 15, n. 1, p. 195-224, mar. 2010.

. Avaliação Quantitativa, Avaliação Qualitativa: Interações e Enfases. In: SGUISSARDI, V. (Org.). Avaliação Universitária em Questão: reformas do Estado e da educação superior. Campinas: Autores Associados, p. 71-89, 1997.

DIMAGGIO, P. J.; POWELL, W. W. Retorno a la Jaula de Hierro. In: W. W. Powell, \& P. J. DiMaggio (Comp.). El Nuevo Institucionalismo en el Análisis Organizacional. México: Fondo de Cultura Económica, p. 104-125, 1999.

ERICHSEN, Hans-Uwe. Tendências europeias na graduação e na garantia da qualidade. Sociologias [on-line]. 2007, n. 17, p. 22-49. 
FREITAS, António Alberto da Silva Monteiro de. Avaliação da Educação Superior no Brasil e Portugal Homogeneização ou Diferenciação. Avaliação, Campinas, [on-line]. 2012. v. 17, n. 1, p. 119-136. Disponível em: <http://dx.doi.org/10.1590/S1414-40772012000100007>. Acesso em: 9 maio de 2012.

GOMES, Candido Alberto. Educação comparada no Brasil: esboço de agenda. Rev. bras. Estud. Pedagog. (on-line), Brasília, v. 96, n. 243, p. 243-288, maio/ago. 2015.

LIMA, Licínio. Avaliação, Competitividade e Hiperburocracia. In: M. P. Alves \& J.-M. De Ketele (Org.). Do Currículo à Avaliação, da Avaliação ao Currículo. Porto: Porto Editora, 2011, p. 71-82.

LIMA, Licínio; AZEVEDO, Mário L. Neves; CATANI, Afrânio Mendes. O processo de Bolonha, a avaliação da educação superior e algumas considerações sobre a Universidade Nova. Avaliação, Campinas; Sorocaba, SP, 2008, v. 13, n. 1, p. 7-36, mar.

MALET, Régis. Do estado-nação ao espaço-mundo: as condições históricas da renovação da educação comparada. Educação e Sociedade, v. 25, n. 89, p. 1301-1332, 2004.

MARQUES, Maria Inês Corrêa; AGUSTI, María Sanches. Processo de Bolonha: reforma e gestão universitária para a internacionalização da educação superior na União Europeia. Revista da Faeeba - Educação e Contemporaneidade, Salvador, v. 21, n. 38, p. 127-138, jul./dez. 2012.

MINED. Ensino Superior em Moçambique: 10 anos em panorama através do PES (2000- 2010). Maputo: Moçambique, 2010.

MINED. Manual de avaliação externa das instituições. Maputo: Moçambique, SINAQES/CNAQ, 2012.

MESCT. MINISTÉRIO DO ENSINO SUPERIOR E DA CIÊNCIA E TECNOLOGIA. Comissão Instaladora do Instituto Nacional de Avaliação e Acreditação do Ensino Superior - CI-INAAES. Relatório de Balanço do Seminário Inter-regional sobre a avaliação e a Acreditação do Ensino Superior. Luanda, 2011.

MOÇAMBIQUE. CONSELHO DE MINISTROS. Boletim da República, de 29 de Setembro de 2009. Maputo: Moçambique, 2009.

MOROSINI, Marília Costa. Estado do conhecimento sobre internacionalização da educação superior - Conceitos e práticas. Educar, Curitiba, n. 28, p. 107-124, 2006.

MOROSINI, Marília Costa; FRANCO, Maria Estela Pai. Educação superior brasileira: encruzilhada na questão da qualidade. In: MACIEL, Adriana Moreira da Rocha, et al. Universidade hoje: o que precisa ser dito?. Santa Maria: Ed. Da UFSM, 2012.

NASCIMENTO, Adão Ferreira do. Os Desafios da Gestão e da Qualidade do Ensino Superior em Angola. Comunicação apresentada no Conselho Consultivo do Ministério do Ensino Superior e da Ciência e Tecnologia. Benguela, 16 e 17 de janeiro de 2012.

PEIXOTO, Maria do Carmo de Lacerda. Avaliação institucional externa no SINAES: considerações sobre a prática recente. Avaliação, Campinas; Sorocaba, v. 16, n. 1, p. 11-36, mar. 2011.

ROMUALDO, Tânia. A Educação no espaço da CPLP. In: CPLP. Pensar, comunicar, actuar em língua portuguesa: 10 ANOS DA CPLP/Comunidade dos Países de Língua Portuguesa. Portugal: Soares da Costa, 2007. 
SANTOS, Boaventura de Sousa. A Universidade no Século XXI: para uma reforma democrática e emancipatória da universidade. In: B. S. Santos \& N. de Almeida Filho. A Universidade no Século XXI: para uma universidade Nova. Coimbra: Almedina, p. 15-78, 2008.

SANTOS, Boaventura de Sousa. Pela mão de Alice: o social e o político na pós-modernidade. São Paulo: Cortez, 1996.

UNESCO. Conferência Mundial sobre Educação Superior (WCHE). Declaração Mundial sobre Educação Superior no Século XXI: Visão e Ação. Paris, 9 de outubro de 1998.

UVALIC-TRUMBIC, Stamenka. A política internacional de garantia de qualidade e credenciamento: de instrumentos legais a comunidades de prática. In: GUNI - Global University Network for Innovation. Educação superior em um tempo de transformação: novas dinâmicas para a responsabilidade social / trad. Vera Muller. Porto Alegre: Edipucrs, 2009.

VARELA, Bartolomeu L. Importância da avaliação das instituições e cursos do ensino superior em Cabo Verde. Cabo Verde: Universidade de Cabo Verde, 2013.

YEREVAN COMMUNIQUÉ. European Higher Education Area (EHEA), Ministerial Conference Yerevan. Yerevan, 14-15 May 2015. 